\title{
DFT modeling of the relative affinity of nitrogen ligands for trivalent f elements: an energetic point of view $\dagger$
}

\author{
Laurence Petit, ${ }^{a b}$ Claude Daul, ${ }^{c}{\text { Carlo } \text { Adamo }^{b} \text { and Pascale Maldivi }}^{* a}$
}

In many theoretical studies dealing with the selective complexation of trivalent actinides with respect to trivalent lanthanides, the method of calculation is assessed by comparing computed geometries with crystal structures that are often available. Yet, the selectivity is better rationalized through thermodynamic data, as enthalpy and entropy terms. In this article, we have theoretically modeled competing complexation reactions of $\left[\mathrm{Ce}(\text { terpy })_{3}\right]^{3+},\left[\mathrm{U}(\text { terpy })_{3}\right]^{3+},\left[\mathrm{Ce}(\mathrm{MeBTP})_{3}\right]^{3+}$ and $\left[\mathrm{U}(\mathrm{MeBTP})_{3}\right]^{3+}$ systems (terpy $=2,2^{\prime}: 6^{\prime} 2^{\prime \prime}$-terpyridine; MeBTP $=$ methyl-2,6-di(1,2,4-triazin3-yl)pyridine) within the framework of the Density Functional Theory. Our calculations manage to qualitatively account for the experimental relative stabilities of terpy and MeBTP complexes, and in particular for the better coordinating strength of MeBTP for trivalent uranium. We also show by comparing the MeBTP ligand with its non-alkylated form (HBTP) that model systems often used in quantum chemistry must be carefully chosen when energetic comparisons are undertaken.

\section{Introduction}

The increasing amount of radioactive waste due to the intensification of nuclear energy programs has created a strong incentive to study means to partition minor trivalent actinides (americium and curium) from trivalent lanthanides Ln. A promising avenue is to identify extractants suited to complex selectively actinides from lanthanides, and then to allow the subsequent transmutation of actinides into short-lived elements. Yet, such a separation process has proved difficult because of the close similarities between trivalent actinide and lanthanide chemical properties, e.g. similar size and reactivity. Their slight differences in hardness (Pearson Hard and Soft Acid Base principle ${ }^{1}$ ) make actinides more prone to develop covalent interactions with soft ligands, and thus provide an attractive solution for $\mathrm{An} / \mathrm{Ln}$ separation. ${ }^{2-5}$

Ligands bearing soft $\mathrm{S}, \mathrm{P}$ and $\mathrm{N}$ atoms have been extensively studied (see for instance ref. 6-11). Tridentate nitrogen molecules were found to feature very good extracting properties, ${ }^{7,12-16}$ and in particular the so-called RBTP (alkylated 2,6di(1,2,4-triazin-3-yl)pyridine) was identified as the most selective nitrogen ligand to date. ${ }^{7,15}$ An effort was made to determine the role of different chemical parameters like substituents, ligand concentration, solvent or number of

\footnotetext{
${ }^{a}$ Laboratoire de Reconnaissance Ionique, DRFMC/LCIB (UMR_E 3 CEA-UJF), CEA-Grenoble, 17 rue des Martyrs, F-38054 Grenoble Cedex 9, France.E-mail: pascale.maldivi@cea.fr; Fax: +3343878 50 90; Tel: +33438785303

${ }^{b}$ Laboratoire d'Electrochimie et de Chimie Analytique, CNRS UMR7575, Ecole Nationale Supérieure de Chimie de Paris, 11 rue Pierre et Marie Curie, F-75231 Paris Cedex 05, France

'Département de Chimie, Université de Fribourg, Pérolles, $\mathrm{CH}-1700$ Fribourg, Switzerland
}

nitrogen atoms onto the extraction efficiency. Such studies, usually based on structural comparisons between actinide and lanthanide complexes, have been enriched by several thermodynamic works. ${ }^{17-24}$ The exploited techniques-e.g. microcalorimetry, spectrophotometry, NMR and mass spectroscopies-have reached sufficient accuracy to differentiate americium and curium behavior from that of lanthanides. They provide a better comprehension of extraction mechanisms by making out the different contributions involved in the complexation process. The entropy contribution was found to be high, in particular for $1: 1$ complexes of MeBTP. Enthalpy terms have also been determined and proved to be strengthened for minor actinides (americium and curium), which was assumed to be in line with a greater amount of covalency within the metal-ligand bond. ${ }^{17,25}$

In this regard, we have recently discussed the reasons of BTP efficiency on the basis of quantum chemistry calculations, ${ }^{26}$ showing that donation on curium $\mathrm{d}$ and $\mathrm{f}$ orbitals may act as a determining factor in its selective complexation to BTP. Theoretical calculations can indeed help in interpreting experimental findings by providing tools for a detailed description of the metal-ligand bond. ${ }^{26-38}$ However, they should not be analyzed without a direct comparison with experiments whereas experimental data are rather scarce, especially for heavy trivalent actinides. To date, theoretical studies dedicated to trivalent rare earth complexes have thus been mainly applied to structural data, with very satisfying agreements, but other computational analyses, and notably energetic analyses, have seldom been validated. ${ }^{39-41}$ Yet, even though structural parameters can account for covalency effects, they cannot differentiate systems on the basis of their relative stability. Only energetic data-complexation constants, free energies - can provide such information and are thus useful to explain the observed selectivity in actinide/ lanthanide extractions. 
<smiles>c1ccc(-c2cccc(-c3ccccn3)n2)nc1</smiles><smiles>[R]c1nnc(-c2cccc(-c3nnc([R])c([R])n3)n2)nc1[R]</smiles>

Fig. 1 terpy $\left(2,2^{\prime}: 6^{\prime} 2^{\prime \prime}\right.$-terpyridine, top) and RBTP [methyl-2,6di(1,2,4-triazin-3-yl)pyridine, bottom] referred to as HBTP if $\mathrm{R}=\mathrm{H}$ and MeBTP if $\mathrm{R}=\mathrm{Me}$.

Among recent studies, experiments conducted by Berthet et al. are particularly interesting because they offer the opportunity to confront quantum chemistry bonding energy trends with experimental data. They have indeed considered the relative affinity of terpy $\left(2,2^{\prime}: 6^{\prime} 2^{\prime \prime}\right.$-terpyridine) and MeBTP (methyl-2,6-di(1,2,4-triazin-3-yl)pyridine) ligands (see Fig. 1) for cerium(III) and uranium(III) by ${ }^{1} \mathrm{H}$ NMR competition experiments. $^{23}$ Three reactions, as listed in Fig. 2, are of special interest: the better coordinating ability of MeBTP than terpy for trivalent $4 \mathrm{f}$ and $5 \mathrm{f}$ cations is illustrated in the first two reactions for which the $1: 3$ metal to MeBTP complex is formed quantitatively at the expense of terpyridine systems for both cerium(III) and uranium(III). The last reaction reveals that MeBTP is more selective for actinide cations (uranium) than for lanthanides (cerium) since the Ce(III) MeBTP complex is evident only after all $1: 3$ uranium systems have been formed.

To rationalize these experimental trends, we have performed energetic calculations with the Density Functional Theory. The $\left[\mathrm{Ce}(\text { terpy })_{3}\right]^{3+},\left[\mathrm{U}(\text { terpy })_{3}\right]^{3+},\left[\mathrm{Ce}(\mathrm{MeBTP})_{3}\right]^{3+}$ and $\left[\mathrm{U}(\mathrm{MeBTP})_{3}\right]^{3+}$ complexes have been considered, focusing first on the relative affinities of the ligands for $f$ elements and next on their selectivities towards actinides. It is also a way to compare two of the major nitrogen ligands involved in $\mathrm{f}$ elements speciation considering their experimental $1: 3$ coordination mode. In particular, the relevance of model systems, often used in calculations, is discussed within the framework of energetic analyses. We comment on the role of alkyl moieties by comparing $\left[\mathrm{M}(\mathrm{HBTP})_{3}\right]^{3+}$ and $\left[\mathrm{M}(\mathrm{MeBTP})_{3}\right]^{3+}$ systems $(\mathrm{M}=\mathrm{Ce}, \mathrm{U})$.

We would like to emphasize that our results are based on a bonding analysis, following an energetic decomposition scheme. Within this approach, we focus on the energetic effects that give insights into the association between the metal and the ligand. Neither entropy nor vibrational terms are assessed as in a regular thermodynamic calculation. In no case can calculated values thus be directly compared with experimental thermodynamic data. Complete thermodynamic calculations are underway, but are obviously more complex to deal with for such large systems. Nevertheless, we show that the bonding and orbital analyses already allow a qualitative agreement with experimental trends to reached, ${ }^{42}$ and the relative selectivity and affinity to be understood. Within this context, the bonding analysis is a well-adapted method because the complexes under study combine several advantages. Experimentally, uranium complexes exhibit lower metal-ligand distances than cerium systems. ${ }^{23}$ This suggests that the difference of selectivity between cerium and uranium is not only related to solvent effects. As we will see below, covalency effects are indeed marked while being appreciably different between cerium and uranium complexes, so the energetic decomposition approach is expected to be fine enough to characterize these differences. Finally, as both metals feature the same $1: 3$ metal to ligand stoichoimetry, we can assume that the entropy term is roughly the same, and thus that it has little influence on relative complexation trends.

\section{Computational details}

All calculations were performed with the ADF package (program release 2004.01). ${ }^{43-45}$ The theoretical treatment of trivalent $\mathrm{f}$ elements complexes with $\mathrm{ADF}$ has been several times investigated. ${ }^{29,33,46,47}$ Density Functional Theory was found to be an effective tool for the description of ground states of the f-elements when applied with the scalar relativistic ZORA approach and the Becke-Perdew GGA functional. ${ }^{48}$ In recent papers, the DFT approach was also found to properly reproduce experimental thermodynamic trends, whereas post Hartree-Fock methods (CASPT2, MP2) were required to reach a better quantitative agreement. ${ }^{40,49}$ The use of such advanced methods for our complexes is obviously too cumbersome. In as far as we are only concerned with reproducing energetic effects qualitatively, the DFT route is thus quite relevant.

Multideterminantal calculations ${ }^{46,50}$ have shown that rare earth compounds generally present a near degeneracy of their $f$ levels, resulting in a weak field configuration for all complexes, namely doublet for $\mathrm{Ce}^{\mathrm{III}}$ and quartet for $\mathrm{U}^{\mathrm{III}}$. Spin-orbit coupling does not significantly influence ground state properties (geometry and frequency), even for open-shell systems. ${ }^{46,51,52}$ In contrast, several studies have shown that it can decrease reaction energies when the charge distribution is strongly modified. ${ }^{53}$ In our systems, the number and the nature of open-shells orbitals are the same in the bare cation and in the complex, so we can assume that spin-orbit effects will roughly compensate one another. As already mentioned in the introduction, absolute $\Delta E$ values are not meaningful, and spin-orbit coupling was thus not taken into account. Adapted

$$
\begin{aligned}
& {\left[\mathrm{Ce}(\text { terpy })_{3}(\mathrm{I})_{3}\right]+3 \text { MeBTP } \longrightarrow \text { py } \longrightarrow\left[\mathrm{Ce}(\mathrm{MeBTP})_{3}\right] \mathrm{I}_{3}+3 \text { terpy }} \\
& {\left[\mathrm{U}(\text { py })_{4}(\mathrm{I})_{3}\right]+3 \mathrm{MeBTP}+3 \text { terpy } \longrightarrow \text { py } \longrightarrow\left[\mathrm{U}(\mathrm{MeBTP})_{3}\right] \mathrm{I}_{3}+3 \text { terpy }+4 \text { py }} \\
& {\left[\mathrm{U}(\text { py })_{4}(\mathrm{I})_{3}\right]+\mathrm{CeI}_{3}+3 \mathrm{MeBTP} \longrightarrow \mathrm{py} \longrightarrow\left[\mathrm{U}(\mathrm{MeBTP})_{3}\right] \mathrm{I}_{3}+\mathrm{CeI}_{3}+4 \text { py }}
\end{aligned}
$$

Fig. 2 Experimental competition reactions (ref. 23, py: pyridine). 
triple- $\zeta$ plus two polarization functions STO basis sets (only one polarization function for $\mathrm{f}$ elements) were used for the description of the valence part of all atoms and we kept their core frozen up to $4 \mathrm{~d} / 5 \mathrm{~d}$ for lanthanides/actinides, and $1 \mathrm{~s}$ for remaining carbon and nitrogen atoms.

The energy of the complexation reaction $\mathrm{M}^{3+}+3 \mathrm{~L} \rightarrow$ $\left[\mathrm{M}(\mathrm{L})_{3}\right]^{3+}$ can be divided into three terms: ${ }^{54}$

$$
\Delta E_{\mathrm{cx}}=\Delta E_{\mathrm{prep}}+\Delta E_{\mathrm{bonding}}+\Delta E_{\mathrm{int}-3 \mathrm{~L}}
$$

$\Delta E_{\text {prep }}$ is referred as the preparatory energy needed to promote the metal and the ligands from their equilibrium geometry to that in the complex. As long as we are dealing with gas phase calculations, the preparatory energy for the cation $\mathrm{M}^{3+}$ cancels. In solution, there are of course solvation effects that are of importance but they should not influence the relative ligand affinity (eqn (1) and (2) in Fig. 2). Moreover, Berthet et al. $^{23}$ have suggested that the affinity and selectivity of the ligands should be related to covalency effects, and for this reason we have focused on the bonding energy $\Delta E_{\text {bonding. }}$

$\Delta E_{\text {bonding }}$ is the energy of interaction between the metal and the ligands taken in the complex equilibrium geometry. The ADF package supplies an energetic decomposition of $\Delta E_{\text {bonding }}$ into chemically meaningful contributions. Such an analysis is based on the transition-state method developed by Ziegler and co-workers. ${ }^{55}$ To sum up, the three ligands $\mathrm{L}$ in their optimized position within the complex are introduced as a single fragment $(3 \mathrm{~L})$, and the interaction of such a fragment (3L) with the metal center is studied. Note in particular that, since the ligand is described by only one fragment, we get rid of the interaction between the 3 ligands $\Delta E_{\text {int-3L }}$ which must be assessed separately. In this manner, we only focus on the metal-ligand interaction. This total bonding energy $\Delta E_{\text {bonding }}$ is then partitioned into:

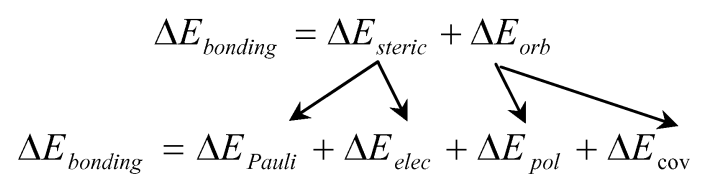

$\Delta E_{\text {steric }}$ is the so-called steric interaction energy between the metal and the 3 ligands and $\Delta E_{\text {orb }}$ is the orbital contribution to the metal-ligand bonds. Note that the steric and the orbitals energy values are meaningless and only their relative trend is to be analyzed. In spite of its name, $\Delta E_{\text {steric }}$ should not be mistaken for the steric repulsive interaction due to bulky systems. Within the scheme of the bonding analysis, it actually arises from the sum of two contributions: $\Delta E_{\text {Pauli }}$ and $\Delta E_{\text {elec }}$. $\Delta E_{\text {Pauli }}$ is the electronic repulsion due to the Pauli principle and is always destabilizing $\left(\Delta E_{\text {Pauli }}>0\right)$. It comes from the orthonormalization of the wave function of $\left[\mathrm{ML}_{3}\right]^{3+}$ built from the orbitals of fragments $\mathrm{M}^{3+}$ and $\mathrm{L}_{3}$. The other contribution, $\Delta E_{\text {elec }}$, is the stabilizing $\left(\Delta E_{\text {elec }}<0\right)$ electrostatic energy between the metal and the ligand fragment $(3 \mathrm{~L})$. It is based on the coulomb interaction between the frozen densities of each fragment. On the whole, the steric energy does not take into account any relaxation effect of the electronic density. The relaxation is included in the orbital term $\Delta E_{\text {orb }}$ that can be also divided into two terms. First, it includes a polarization term $\Delta E_{\mathrm{pol}}$ caused by the reorganization of the metal and ligand electronic densities during the complexation process. Covalency may also appear if the metal and ligands orbitals overlap. Unfortunately, $\Delta E_{\mathrm{pol}}$ and $\Delta E_{\mathrm{cov}}$ cannot be quantified separately and only $\Delta E_{\text {orb }}$ can be calculated. When dealing with high-symmetry systems, donation and backdonation can in principle be separated through a partitioning of the orbital energy into the contributions from distinct irreducible representations. This analysis cannot be performed for our complexes because, in agreement with the experimental structure, there is no symmetry. Finally, the Basis Set Superposition Error (BSSE) was assessed on HBTP complexes and was found to be low enough $(\approx 0.3 \mathrm{eV})$ in comparison to the computed $\Delta E$ values.

Berthet et al. ${ }^{23}$ have carried out their reactions in pyridine and acetonitrile without any strong coordinating counter-ion in order to favor the 1:3 metal to ligand ratio. Note however that, whereas such a stoichiometry is effectively found for RBTP complexes under extraction conditions, ${ }^{15,19,56,57}$ terpy generally presents lower and variable stoichiometries with $f$ elements. $^{23,58}$ Yet, this $1: 3$ coordination mode is interesting therein for three main reasons. First, it has been clearly characterized $^{23}$ so no assumption has to be made in this regard. It also excludes counter-ion from the first coordination sphere whereas several theoretical works have shown that, when counter-ions are present within the first coordination shell, the nature of the metal-ligand bond can be strongly affected. ${ }^{31,59,60}$ Finally, both cerium and uranium complexes present the same coordination sphere, and solvent effects should be rather similar. Therefore, as far as we are interested in relative trends, it is not useful to take them into account.

Even so, a test was performed with the continuum dielectric solvent model ( $\varepsilon=12.4$ for pyridine) COSMO (COnductor like Screening Model), ${ }^{61-63}$ as implemented in the ADF package. Following a previous work, ${ }^{64}$ atomic radii were taken from literature ${ }^{65}$ with a scaling factor of $0.833\left(r_{\mathrm{La}}=2.32\right.$; $\left.r_{\mathrm{N}}=1.61 ; r_{\mathrm{C}}=1.70 ; r_{\mathrm{H}}=1.35\right)$. Results for the $\left[\mathrm{La}(\mathrm{MeBTP})_{3}\right]^{3+}$ complex are provided in the supporting information $\dagger$, but no significant difference between vacuo and pyridine media is observed.

\section{Results}

Crystal structures of terpy and MeBTP complexes ${ }^{23}$ were used as starting points for our optimizations. For the U-MeBTP complex, only the $\left[\mathrm{U}(\operatorname{PrBTP})_{3}\right]^{3+}$ experimental geometry was available, so methyl substituents were introduced in place of propyl moieties. Geometries were fully optimized and mean $\mathrm{M}-\mathrm{N}$ distances are collected in Table 1, with the experimental reference ${ }^{23}$ mentioned in parentheses. Both terpy and MeBTP geometries fit very well the experimental values. The mean discrepancy is in the order of $0.02 \AA$, while the highest difference does not exceed $0.06 \AA$. The evolution of uranium distances to central $\left(\mathrm{N}_{\mathrm{c}}\right)$ and lateral $\left(\mathrm{N}_{1}\right)$ nitrogen atoms is however badly reproduced. The distance to the central nitrogen atom is systematically too low with respect to lateral rings. For cerium systems, $\mathrm{U}-\mathrm{N}_{1}$ distances are smaller than $\mathrm{U}-\mathrm{N}_{\mathrm{c}}$ ones, in contrast with transition metals for which a greater extent of covalency with the central pyridine ring has been reported. ${ }^{66}$ But the most important observation is the 
Table 1 Calculated metal-ligand distances for terpy, MeBTP and HBTP complexes of Ce $\mathrm{e}^{\mathrm{III}}$ and $\mathrm{U}^{\mathrm{III}} \cdot{ }^{a}$ Experimental values ${ }^{23}$ are reported in parentheses

\begin{tabular}{lcccccc}
\hline & {$\left[\mathrm{Ce}(\text { terpy })_{3}\right]^{3+}$} & {$\left[\mathrm{U}(\text { terpy })_{3}\right]^{3+}$} & {$\left[\mathrm{Ce}(\mathrm{MeBTP})_{3}\right]^{3+}$} & {$\left[\mathrm{U}(\mathrm{MeBTP})_{3}\right]^{3+}$} & {$\left[\mathrm{Ce}(\mathrm{HBTP})_{3}\right]^{3+}$} & {$\left[\mathrm{U}(\mathrm{HBTP})_{3}\right]^{3+b}$} \\
\hline$d\left(\mathrm{M}-\mathrm{N}_{\mathrm{c}}\right) / \AA$ & $2.68(2.662 \pm 0.0007)$ & $2.56(2.623 \pm 0.0002)$ & $2.64(2.64 \pm 0.002)$ & $2.53\left(2.55 \pm 0.002^{c}\right)$ & 2.65 & 2.54 \\
$d\left(\mathrm{M}-\mathrm{N}_{\mathrm{l}}\right) / \AA$ & $2.68(2.64 \pm 0.004)$ & $2.62(2.63 \pm 0.004)$ & $2.63(2.61 \pm 0.002)$ & $2.56\left(2.54 \pm 0.002^{c}\right)$ & 2.63 & 2.57 \\
${ }^{a} \mathrm{~N}_{\mathrm{c}}$ : central nitrogen atom; $\mathrm{N}_{1}$ : lateral nitrogen atom. ${ }^{b}$ See ref. $26^{c}$ Experimental reference for $\left[\mathrm{U}(\mathrm{iPrBTP})_{3}\right]^{3+}$. & \\
\hline
\end{tabular}

significant shortening of $\mathrm{U}-\mathrm{N}$ distances with respect to those in cerium complexes, especially as uranium and cerium cations are similarly sized: the mean $\mathrm{U}-\mathrm{N}$ distances are indeed found $0.08 \AA$ smaller than $\mathrm{Ce}-\mathrm{N}$ in MeBTP and terpy systems, vs. 0.09 and $0.03 \AA$ for the experimental contraction. This effect is the main indication of a larger amount of covalency in $\mathrm{U}-\mathrm{N}$ bonds at the experimental level, and has been several times rationalized in terms of $\pi$ back-bonding interactions between uranium $5 \mathrm{f}$ orbitals and the ligand $\pi^{*}$ levels. ${ }^{23,30,33,67-69}$

To better understand the balance of the different contributions at stake in the metal-ligand association, the complexation energy $\Delta E_{\mathrm{cx}}$ has been partitioned, as described in the computational details. The preparation energy $\Delta E_{\text {prep, }}$, the ligands interaction $\Delta E_{\text {int-3L }}$ and the bonding energy $\Delta E_{\text {bonding }}$ are listed in Table 2. We remind the reader that no quantitative comparison with experimental data should be made. The preparation energy is computed as the difference between the energy of each ligand in the complex geometry and in its equilibrium position. This is obviously an approximation because solvent effects are not taken into account. Yet, pyridine being a non-protic solvent, no drastic change between terpy and MeBTP is expected. Actually, we only aim at showing that discrepancies between cerium and uranium are not significant, and thus that the preparation energy is not of major importance in relative stabilities. Next line in Table 2, the interaction energy $\Delta E_{\text {int-3L }}$ of the 3 ligands in the complex geometry is assessed. Differences are also found to be negligible. The main discrepancies are calculated for the bonding energy $\Delta E_{\text {bonding }}$ that is to say for the interaction energy between the metal and the ligands taken as a unique fragment. This is the focus of the bonding analysis.

Fig. 3 (upper diagram) shows the different contributions to the metal-ligand bond for terpy and MeBTP complexes. For practical reason, the steric energy is displayed, but the decomposition into the Pauli and the electrostatic terms is given in the supplementary information $\dagger$. On the whole, MeBTP complexes systematically present lower total bonding energies than their terpy analogues, while the uranium-ligand interaction is found to be more stabilizing than that of cerium. For the latter, the contraction of $\mathrm{U}-\mathrm{N}$ distances logically results in a strengthening of the Pauli electronic repulsion, and explains

Table 2 Evaluation of the relative stabilities for terpy and MeBTP complexes

\begin{tabular}{lcccc}
\hline & {$\left[\mathrm{Ce}(\text { terpy })_{3}\right]^{3+}\left[\mathrm{U}(\text { terpy })_{3}\right]^{3+}\left[\mathrm{Ce}(\mathrm{MeBTP})_{3}\right]^{3+}\left[\mathrm{U}(\mathrm{MeBTP})_{3}\right]^{3+}$} \\
\hline$\Delta E_{\text {prep }} / \mathrm{eV}$ & 2.10 & 2.31 & 0.10 & 0.67 \\
$\Delta E_{\text {int }-3 \mathrm{~L} / \mathrm{eV}} / 1.31$ & 1.53 & 1.52 & 1.65 \\
$\Delta E_{\text {bonding }} / \mathrm{eV}$ & -29.32 & -30.62 & -30.91 & -31.94 \\
$\Delta E_{\mathrm{cx}} / \mathrm{eV}$ & -25.91 & -26.78 & -29.29 & -29.62 \\
\hline
\end{tabular}

why uranium complexes feature lower steric terms (in absolute value) than cerium counterparts $\left(\left|\Delta\left(\Delta E_{\text {steric }}\right)\right|=11.5 \mathrm{eV}\right.$ for terpy ligand and $12.7 \mathrm{eV}$ with MeBTP). Note that steric and orbital absolute energy values have no direct chemical significance, and only trends can be exploited. The orbital term is also lower for uranium complexes, and thus suggests a higher covalency. As indicated in the computational details, the polarization effects due to the relaxation of the orbitals are included in $\Delta E_{\text {orb. }}$. In the absence of counter-ions, the high metallic charge induces a significant polarization of the ligands that strongly contributes to the computed orbital energies. In particular, uranium-ligand distances are shorter than in cerium complexes, and polarization must be higher therein. Since polarization cannot be computed independently of the covalent part, a reliable comparison of covalency between cerium and uranium systems is thus hindered.

As proposed by Lein et al., ${ }^{54}$ the ratio between the electrostatic term $\Delta E_{\text {elec }}$ and the orbital contribution $\Delta E_{\text {orb }}$ can provide a measure of the degree of covalency within the metal-ligand bond. Yet, when polarization is the main contribution to the orbital term as is the case here, it actually leads to misleading values. The percentage contributions of the orbital and electrostatic parts to the metal-ligand bond have been computed and results are given in the supporting information (SI3) $\dagger$. They suggest that the metal-ligand bond is mainly covalent whereas, despite slight covalent effects, the bond should be mainly electrostatic. Moreover, no clear distinction between the different complexes is observed.

To probe the influence of the metal cation, we have carried out a similar bonding analysis considering the uranium cation within the geometry of the cerium complexes and vice versa. This should allow the energetic variations induced by the cation to be separated from those related to the metal-ligand distances. Results are shown in the supporting information $\dagger$. It is interesting to note that the electrostatic term is not affected by the metal cation within the same complex geometry because trivalent cerium and uranium cations have a similar ionic radius. In contrast, the polarization term may be different as it depends on the charge distribution. Similarly, the Pauli repulsion systematically decreases with the cerium atom as the number of electrons is lower than for uranium. When $\mathrm{Ce}^{3+}$ is inserted instead of uranium within the complex, Ce-N distances are then shorter than in the equilibrium position, and the orbital contribution is logically strengthened. In particular, back-bonding effects increase: $+0.08\left|\mathrm{e}^{-}\right|$with terpy, +0.09 $\left|\mathrm{e}^{-}\right|$for MeBTP. With the terpy ligand, this stabilization is strong enough to compensate the steric term, and the $\mathrm{Ce}-\mathrm{N}$ bond of the $\left[\mathrm{Ce}(\text { terpy })_{3}\right]^{3+}$ complex in the uranium geometry is then more stabilized $\left(\Delta E_{\text {bonding }}\right)$ than $\left[\mathrm{Ce}(\text { terpy })_{3}\right]^{3+}$ in its ground state. With MeBTP, structural differences between 


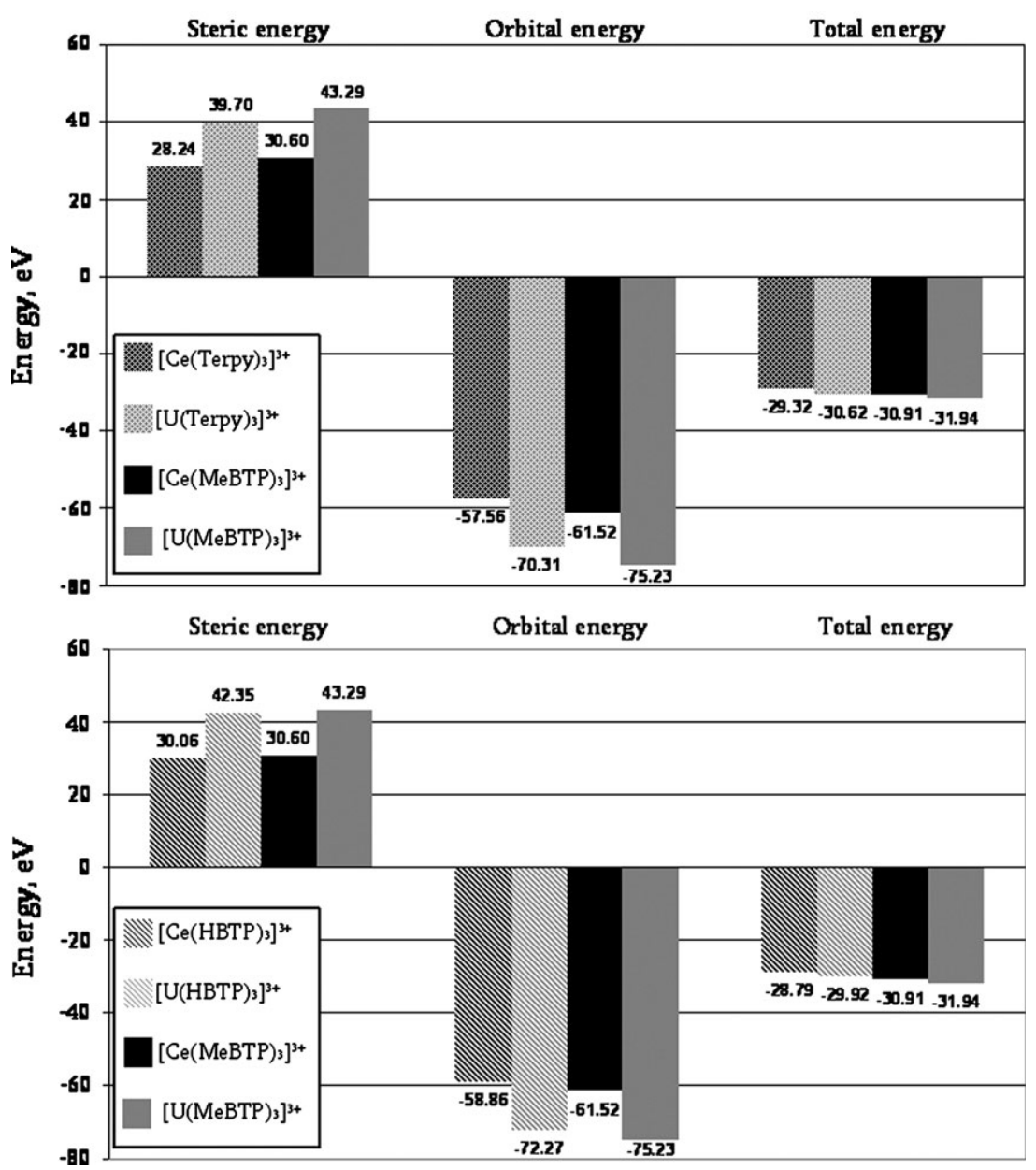

Fig. 3 Energetic decomposition of the different contributions involved in the complexation process of $\mathrm{M}^{3+}$ by 3 ligands. Top: terpy vs. MeBTP. Bottom: HBTP vs. MeBTP.

uranium and cerium complexes are more pronounced and the destabilizing steric contribution is then more important. With both ligand however, backdonation remains systematically higher for uranium systems. This confirms that, despite structural differences, the uranium cation is indeed more prone to develop back-bonding interactions.

An orbital analysis, investigating how electrons are distributed between metals and ligands levels, tells us more about covalency effects. Generally, frontier orbitals in Ln and An complexes have a predominant $f$ character. As far as $f$ orbitals are partially filled, donation and/or backdonation can occur through a mixing with the ligand orbitals. In practice, backdonation is assessed as the amount of the ligand vacant $\pi^{*}$ orbitals onto the metal occupied $\mathrm{f}$ orbitals $\left(4 \mathrm{f}^{1}\right.$ for Ce and $5 \mathrm{f}^{3}$ for $\mathrm{U})$. The amount of electrons retrieved by the ligand orbitals is indicated for each complex in Fig. 4. Appreciable backdonation is found in uranium complexes $\left(0.59\left|\mathrm{e}^{-}\right|\right.$in $\left.\left[\mathrm{U}(\mathrm{MeBTP})_{3}\right]^{3+}\right)$ and to a lesser extend for cerium $\left(0.16\left|\mathrm{e}^{-}\right|\right.$in $\left.\left[\mathrm{Ce}(\mathrm{MeBTP})_{3}\right]^{3+}\right)$. Differences between the MeBTP and terpy ligands are also particularly marked. In contrast, donation on metal vacant $\mathrm{f}$ and $\mathrm{d}$ orbitals has not been specified because differences from one system to another are less pronounced. Note however that donation is slightly enhanced in terpy systems with respect to MeBTP: $+0.10\left|\mathrm{e}^{-}\right|$on cerium $5 \mathrm{~d}$ levels and $+0.12\left|\mathrm{e}^{-}\right|$for $6 \mathrm{~d}(\mathrm{U})$.

\section{Discussion}

Relative coordinating ability of MeBTP vs. terpy

Reactions (1) and (2) (Fig. 2) suggest the stronger affinity of MeBTP than terpy towards the complexation of both cerium and uranium trivalent cations since MeBTP complexes are

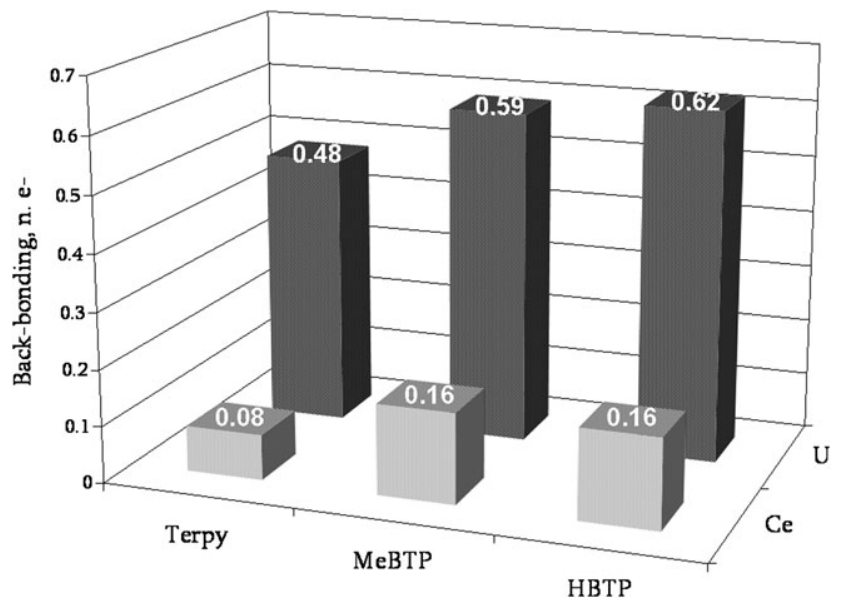

Fig. 4 Amount of backdonation (number of electrons, $n . \mathrm{e}^{-}$) for cerium and uranium 1:3 complexes of terpy, MeBTP and HBTP. 
formed in preference. Our energetic calculations support this observation (Total bonding energies, Fig. 3-upper diagram). The interaction of cerium and uranium atoms with the MeBTP ligand is found to be, respectively $1.59 \mathrm{eV} / 1.32 \mathrm{eV}(36.70 \mathrm{kcal}$ $\mathrm{mol}^{-1} / 30.44 \mathrm{kcal} \mathrm{mol}^{-1}$ ) more stable than their terpy counterparts because of the strengthening of the orbital term. The lateral pyridines within the terpyridine scaffold are replaced in MeBTP by 1,3,5 triazines. The softer character of triazine nitrogen atoms makes MeBTP weakly basic and enhanced covalency is thus expected. To better understand these effects, Fig. 5 presents the orbital diagram of ligand fragments $(3 \mathrm{~L})$ as they are used for the calculation of energetic data. Frontier orbitals are very similar for the three ligands. The Highest Occupied Molecular Orbital (HOMO) has a $\sigma$ character between nitrogen and carbon atoms $\left(\sigma_{\mathrm{CN}}\right)$ while the first vacant orbitals (LUMOs, Lowest Unoccupied Molecular Orbitals) are found to be antibonding $\pi$ levels. Considering that the HOMO-LUMO gap is proportional to the absolute hardness, ${ }^{70}$ the lower hardness of MeBTP with respect to terpy clearly appears in Fig. 5. On one hand, occupied $\sigma \mathrm{CN}$ levels in terpyridine are found lower in energy than MeBTP $\sigma$ orbitals because pyridine nitrogen atoms are more basic than those in triazine rings. The interaction with the metal vacant $\mathrm{d}$ and $\mathrm{f}$ orbitals is then stronger, which supports the better donation found in terpy complexes. On the other hand, its $\pi^{*}$ orbitals are moved to higher energies, reducing the possible mixing with the metal occupied $\mathrm{f}$ levels, and therefore the backbonding magnitude (see Fig. 4). For comparison, 4d/5d and $4 \mathrm{f} / 5 \mathrm{f}$ orbitals in cerium and uranium complexes are around -0.4 a.u. and -0.23 a.u., respectively, that is to say below the ligands frontier orbitals.

HBTP results are also presented since HBTP is usually taken as a model for alkyl-BTP compounds in theoretical studies. $^{26,31}$ In MeBTP, alkyl moieties are introduced onto BTP side arms (see Fig. 1) in order to strengthen the ligand hydrophobicity, prerequisite for enhancing its extraction power. ${ }^{3}$ Resistance to hydrolysis and radiolysis is also of major concern for a potential use of BTP at the industrial scale. ${ }^{15}$ Various studies have proved that they contribute to the exceptional 1:3 stoichiometry of alkyl-BTP ligands by limiting protonation and H-bonding. ${ }^{16,19}$ Neglecting alkyl groups is thus not trivial, ${ }^{71}$ and for this reason we felt that it was relevant to investigate HBTP and MeBTP properties.

On the whole, structural differences between HBTP and MeBTP complexes are low. In Table 1, metal-nitrogen distances are hardly affected and electronic properties are also comparable. Alkyl moieties have an inductive donor character, a property several times exploited to modulate the metal-ligand bond in cyclopentadienyl complexes of $\mathrm{f}$ elements. $^{21,22}$ Nitrogen atoms in MeBTP are thus expected to be more basic, which logically makes MeBTP slightly harder than HBTP. This is consistent with the decrease of the

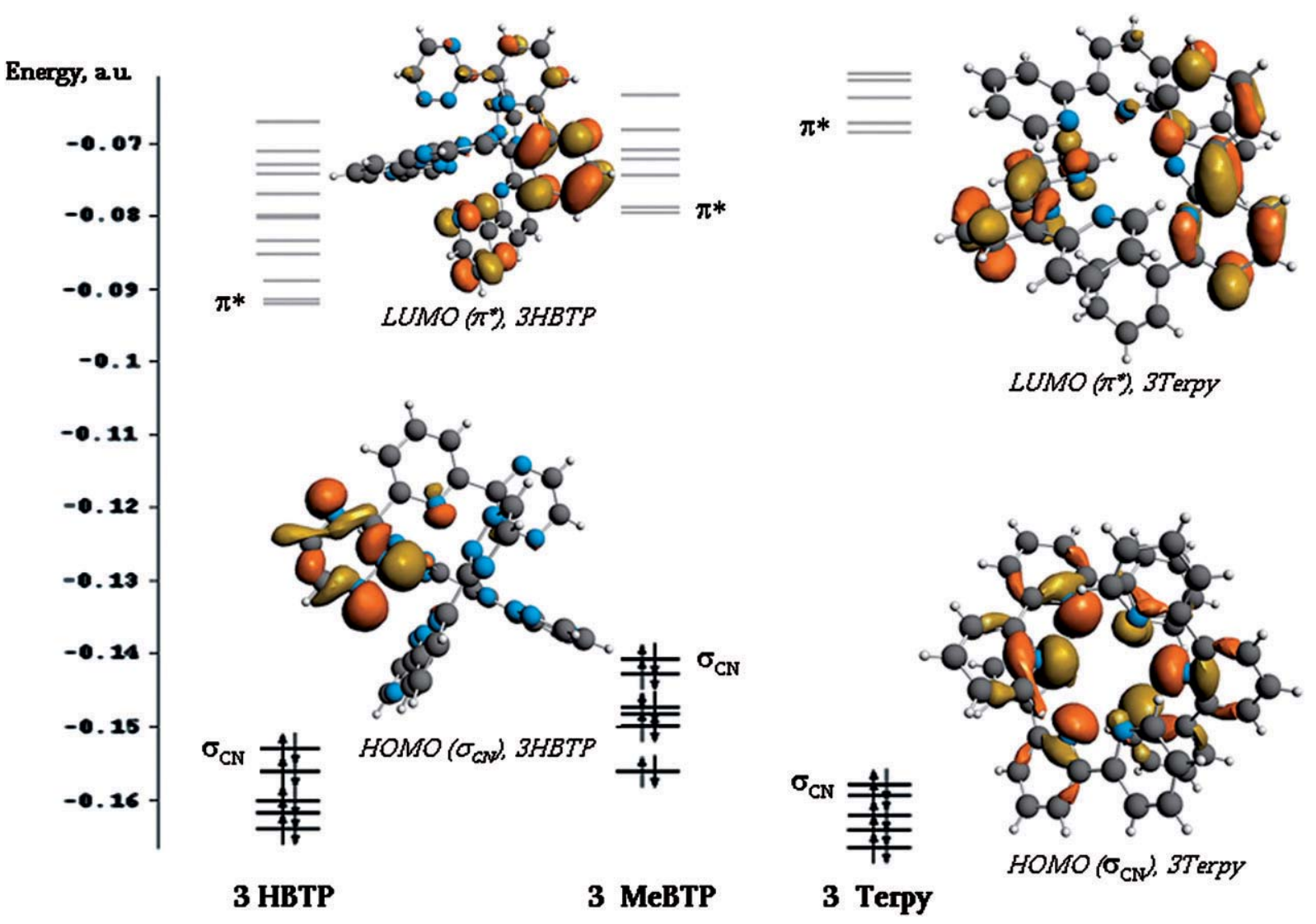

Fig. 5 Orbital diagram of $3 \mathrm{~L}, \mathrm{~L}=$ HBTP, MeBTP and terpy, with corresponding localized molecular orbital pictures of HOMO (Highest Occupied Molecular Orbital) and LUMO (Lowest Unoccupied Molecular Orbitals). HBTP and MeBTP ligands present similar orbital patterns and only HBTP HOMO and LUMO are thus displayed. 
HOMO/LUMO gap from MeBTP to HBTP in Fig. 5. Yet, donation and backdonation (Fig. 4) are found to be roughly similar for both ligands.

Actually, the main difference is observed when we focus on the energetic analysis (see Fig. 3-lower diagram, and supporting information $\dagger$ ). MeBTP is more basic than HBTP, and its electrostatic interaction with the metal cation is thus stronger. The electrostatic term is indeed higher (in absolute values) for both cerium and uranium MeBTP complexes than for their HBTP counterparts $\left(\left|\Delta\left(\Delta E_{\text {elec }}\right)\right|=0.35 \mathrm{eV}\right.$ and $0.55 \mathrm{eV}$, respectively). The orbital term also increases, and in as far as there is no strong difference of covalency between HBTP and MeBTP (Fig. 4), this must be due to polarization effects. On the whole, the introduction of methyl substituents stabilizes $\Delta E_{\text {bonding }}$ in MeBTP complexes of $c a .2 .0 \mathrm{eV}$. It is interesting to note that this electrostatic stabilization does not depend on the metal center, and is only the result of the alkyl moieties. Indeed, an attempt was made with other metals (La, Cm) and the very same stabilization of $c a .2 .0 \mathrm{eV}$ for MeBTP systems was calculated. Such electrostatic effects participate in making MeBTP complexes more stable than terpy systems, in agreement with experimental data. ${ }^{23}$ In contrast, the total bonding energy of HBTP complexes is found lower than that of terpyridine systems. As a result, HBTP becomes inadequate when comparing ligand affinities and it is then necessary to take the methyl moieties into account. Note, however, that the magnitude of covalency is roughly similar for MeBTP and HBTP complexes, and therefore the HBTP ligand remains a relevant model system for qualitative comparisons of covalency effects, i.e. for the analysis of the relative selectivity for lanthanides and actinides. This confirms the major role of alkyl moieties in actinide/ lanthanide extraction processes and proves how important the choice of relevant model systems is.

\section{MeBTP selectivity towards actinides}

The last competition reaction presented in Fig. 2 demonstrates the higher selectivity of MeBTP for actinides: in a mixture of cerium and uranium salts, the uranium complex is formed in preference while no cerium counterpart is observed. Indeed, the computed bonding energies show a significant stabilization of $1.03 \mathrm{eV}\left(23.75 \mathrm{kcal} \mathrm{mol}^{-1}\right)$ of $\left[\mathrm{U}(\mathrm{MeBTP})_{3}\right]^{3+}$ with respect to the cerium analogue. As suggested by the shortening of U-N distances, MeBTP selectivity is caused by stronger backbonding effects within uranium-ligand bonds. Fig. 4 confirms this observation, with as many as 0.59 electrons withdrawn from uranium to MeBTP $v s$. only $0.16\left|\mathrm{e}^{-}\right|$for cerium.

Although not present in nuclear spent fuels, trivalent uranium is less radioactive and can be more easily handled than minor actinides (americium and curium), explaining why it is commonly used as a surrogate for americium and curium. ${ }^{20-24}$ Cerium III has a similar ionic radius to $U^{\text {III }}$ (for identical coordination numbers) and is considered as representative of the lanthanide series. Our energetic analysis supports the better selectivity of MeBTP for uranium because of enhanced backdonation. Despite this, we have previously shown that such effects did not occur in $\left[\mathrm{Cm}(\mathrm{HBTP})_{3}\right]^{3+}$ where only donation was observed. ${ }^{26} \mathrm{We}$ checked that $\left[\mathrm{Cm}(\mathrm{MeBTP})_{3}\right]^{3+}$ behaved in the same way. It actually turns out that trivalent cerium and uranium feature an atypical behavior: their $\mathrm{f}$ orbitals are more diffuse than other rare-earth atoms, which logically increases their interaction with surrounding ligands. They are indeed almost the only f elements for which backdonation is found, in line with their well-known easy oxidation to $\mathrm{M}^{\mathrm{IV}}$. Thus, they cannot be considered as appropriate models for studying lanthanides/actinides extraction process. They can just be viewed as reference systems since experimental data are more available for such metals.

\section{Conclusion}

The modeling of thermodynamics trends with quantum chemistry methods is very challenging as its aim is to understand the different phenomena involved in actinide/lanthanide separation processes. Our DFT energetic calculations on terpy and MeBTP complexes of trivalent cerium and uranium show a good qualitative agreement with competition reactions: they confirm that MeBTP features an increased affinity for both metals (Ce, U) with respect to terpy as well as a better selectivity for uranium because of stronger backdonation effects. A similar energetic comparison using HBTP instead of MeBTP would have led to erroneous conclusions, reminding us that alkyl moieties have a determining role in the design of substituted BTP. Similarly, cerium and uranium atoms prove to be poor models for the study of actinide/lanthanide selective extraction since covalency is then largely aggravated. This shows once more that choosing suitable model systems is a crucial point.

In summary, the bonding analysis as used in this study provides useful insights into the nature of the chemical bond as it helps to explain qualitatively complex stabilities. This prepares the ground for real thermodynamic calculations including entropy, temperature and solvent effects. Comparisons of complexes with metals really involved in nuclear spent fuel (Am, Cm) will then be possible.

\section{Acknowledgements}

This work was supported by the Swiss National Science Foundation and the CEA/Nuclear Energy Division. We wish to thank J.-C. Berthet for useful remarks and suggestions.

\section{References}

1 (a) R. G. Pearson, Chemical hardness, Wiley-VCH, New York, 1997; (b) R. G. Pearson, J. Am. Chem. Soc., 1963, 85, 3533.

2 R. M. Diamond, K. Street, Jr and G. T. Seaborg, J. Am. Chem. Soc., 1954, 76, 1461.

3 K. L. Nash, 'Separation chemistry for lanthanides and trivalent actinides', in Handbook on Physics and Chemistry of Rare Earths, ed. K. A. Gschneidner, Jr, L. Eyring, G. R. Choppin and G. H. Lander, 1994, Elsevier/North Holland, vol. 18, p. 197.

4 G. R. Choppin, J. Less-Common Met., 1983, 93, 323.

5 C. Musikas, C. Cuillerdier, J. Livet, A. Forchioni and C. Chachaty, Inorg. Chem., 1983, 22, 2513.

6 Y. Zhu, Radiochim. Acta, 1995, 68, 95.

7 (a) Z. Kolarik, U. Müllich and F. Gassner, Solvent Extr. Ion Exch., 1999, 17, 23; (b) Z. Kolarik, U. Müllich and F. Gassner, Solvent Extr. Ion Exch., 1999, 17, 1155.

8 P. Y. Cordier, C. Hill, P. Baron, C. Madic, M. J. Hudson and J. O. Liljenzin, J. Alloys Compd., 1998, 271-273, 738. 
9 M. Weigl, M. A. Denecke, P. J. Panak, A. Geist and K. Gompper, Dalton Trans., 2005, 1281.

10 M. P. Jensen and A. H. Bond, J. Am. Chem. Soc., 2001, 124, 9870.

11 G. R. Choppin and K. L. Nash, Radiochim. Acta, 1995, 70/71, 225.

12 J. L. Sessler, P. J. Melfi and G. Dan Pantos, Coord. Chem. Rev., 2006, 250, 816.

13 L. Karmazin, M. Mazzanti, C. Gateau, C. Hill and J. Pecaut, Chem. Commun., 2002, 2892.

14 M. R. S. Foreman, M. J. Hudson, M. G. B. Drew, C. Hill and C. Madic, Dalton Trans., 2006, 1645.

15 M. J. Hudson, C. E. Boucher, D. Braekers, J. F. Desreux, M. G. B. Drew, M. R. St J. Foreman, L. M. Harwood, C. Hill, C. Madic, F. Marken and T. G. A. Youngs, New J. Chem., 2006, 30, 1171.

16 M. G. B. Drew, C. Hill, M. J. Hudson, P. B. Iveson, C. Madic, L. Vaillant and T. G. A. Youngs, New J. Chem., 2004, 28, 462.

17 M. Miguirditchian, D. Guillaneux, D. Guillaumont, P. Moisy, C. Madic, M. P. Jensen and K. L. Nash, Inorg. Chem., 2005, 44, 1404.

18 M. Miguirditchian, D. Guillaneux, N. Francois, S. Airvault, S. Ducros, D. Thauvin, C. Madic, M. Illemassene, G. Lagarde and J. C. Krupa, Nucl. Sci. Eng., 2006, 153, 223.

19 (a) S. Colette, B. Amekraz, C. Madic, L. Berthon, G. Cote and C. Moulin, Inorg. Chem., 2002, 41, 703; (b) S. Colette, B. Amekraz, C. Madic, L. Berthon, G. Cote and C. Moulin, Inorg. Chem., 2003, 42, 2215; (c) S. Colette, B. Amekraz, C. Madic, L. Berthon, G. Cote and C. Moulin, Inorg. Chem., 2004, 43, 6745.

20 C. Rivière, M. Nierlich, M. Ephritikhine and C. Madic, Inorg. Chem., 2001, 40, 4428.

21 T. Mehdoui, J.-C. Berthet, P. Thuéry and M. Ephritikhine, Dalton Trans., 2004, 579.

22 T. Mehdoui, J.-C. Berthet, P. Thuéry and M. Ephritikhine, Eur. J. Inorg. Chem., 2004, 1996.

23 (a) J.-C. Berthet, Y. Miquel, P. B. Iveson, M. Nierlich, P. Thuéry, C. Madic and M. Ephritikhine, J. Chem. Soc., Dalton Trans., 2002, 3265; (b) P. B. Iveson, C. Rivière, M. Nierlich, P. Thuéry, M. Ephritikhine, D. Guillaneux and C. Madic, Chem. Commun., 2001, 1512.

24 J.-C. Berthet, M. Nierlich, Y. Miquel, C. Madic and M. Ephritikhine, Dalton Trans., 2005, 369.

25 M. Miguirditchian, Etude Thermodynamique de la complexation des ions actinide(III) et lanthanide(III) par des ligands polyazotés en milieu homogène, rapport CEA-R- 6059, 2004.

26 L. Petit, C. Adamo and P. Maldivi, Inorg. Chem., 2006, 45, 8517.

27 L. Petit, L. Joubert, P. Maldivi and C. Adamo, J. Am. Chem. Soc., 2006, 128, 2190.

28 L. Maron and O. Eisenstein, J. Phys. Chem. A, 2000, 104, 7140.

29 D. Guillaumont, J. Phys. Chem. A, 2004, 108, 6893.

30 V. Vetere, P. Maldivi and C. Adamo, Int. J. Quantum Chem., 2003, 91, 321.

31 D. Guillaumont, J. Mol. Struct. (THEOCHEM), 2006, 771, 105.

32 J. L. Sonnenberg, P. J. Hay, R. L. Martins and B. E. Bursten, Inorg. Chem., 2005, 44, 2255.

33 N. Kaltsoyannis, Chem. Soc. Rev., 2003, 32, 9.

34 M. Straka, P. Hrobarik and M. Kaupp, J. Am. Chem. Soc., 2005, 127, 2591.

35 M. Pepper and B. E. Bursten, Chem. Rev., 1991, 91, 719.

36 M. Roger, N. Barros, T. Arliguie, P. Thuery, L. Maron and M. Ephritikhine, J. Am. Chem. Soc., 2006, 128, 8790.

37 L. Perrin, L. Maron and O. Eisenstein, Faraday Discuss., 2003, 124, 25.

38 M. Roger, L. Belkhiri, P. Thuéry, T. Arliguie, M. Fourmigué, A. Boucekkine and M. Ephritikhine, Organometallics, 2005, 24, 4940.
39 J. Wiebke, A. Moritz, X. Cao and M. Dolg, Phys. Chem. Chem. Phys., 2007, 9, 459.

40 L. Gagliardi and C. J. Cramer, Inorg. Chem., 2006, 45, 9442.

41 Z. Szabo, T. Toraishi, V. Vallet and I. Grenthe, Coord. Chem. Rev., 2006, 250, 784

42 T. Ziegler and A. Rauk, Inorg. Chem., 1979, 18, 1755.

43 E. J. Baerends, D. E. Ellis and P. Ros, Chem. Phys., 1993, 2, 42.

44 P. M. Boerrigter, G. te Velde and E. J. Baerends, Int. J. Quantum Chem., 1988, 33, 87.

45 G. te Velde and E. J. Baerends, Comput. Phys., 1992, 99, 84.

46 V. Vetere, B. O. Roos, P. Maldivi and C. Adamo, Chem. Phys. Lett., 2004, 396, 452.

47 V. Vetere, P. Maldivi and C. Adamo, J. Comput. Chem., 2003, 24, 850.

48 (a) A. D. Becke, Phys. Rev. A, 1988, 38, 3098; (b) J. P. Perdew, Phys. Rev. B: Solid State, 1986, 33, 8822.

49 K. E. Gutowski and D. A. Dixon, J. Phys. Chem. A, 2006, 110, 8840.

50 J. V. Ortiz, P. J. Hay and R. L. Martin, J. Am. Chem. Soc., 1992, 114, 2736.

51 V. Vallet, P. Macak, U. Walgren and I. Grenthe, Theor. Chem. Acc., 2006, 115, 145.

52 C. Clavaguéra-Sarrio, V. Vallet, D. Maynau and C. J. Marsden, J. Phys. Chem. A, 2004, 121, 5312.

53 V. Vallet, B. Schimmelpfennig, L. Maron, C. Teichteil, T. Leininger, O. Gropen, I. Grenthe and U. Walgren, Chem. Phys., 1999, 244, 185.

54 M. Lein, A. Szabo, A. Kovacs and G. Frenking, Faraday Discuss., 2003, 124, 365.

55 T. Ziegler and A. Rauk, Theor. Chim. Acta, 1977, 46, 1.

56 M. A. Denecke, A. Rossberg, P. J. Panak, M. Weigl, B. Schimmelpfennig and A. Geist, Inorg. Chem., 2005, 44, 8418.

57 M. G. B. Drew, D. Guillaneux, M. J. Hudson, P. B. Iveson, M. L. Russell and C. Madic, Inorg. Chem. Commun., 2001, 4, 12.

58 J.-C. Berthet, C. Rivière, Y. Miquel, M. Nierlich, C. Madic and M. Ephritikhine, Eur. J. Inorg. Chem., 2002, 1439.

59 P. Maldivi, L. Petit, C. Adamo and V. Vetere, C. R. Chim., 2007, in press.

60 L. Troxler, A. Dedieu, F. Hutschka and G. Wipff, J. Mol. Struct. (Theochem), 1998, 431, 151.

61 A. Klamt and G. Schüürmann, J. Chem. Soc., Perkin Trans., 1993, 2, 799 .

62 A. Klamt, J. Phys. Chem., 1995, 99, 2224

63 A. Klamt and V. Jones, J. Chem. Phys., 1996, 105, 9972.

64 R. S. Bon, B. van Vliet, N. E. Sprenkels, R. F. Schmitz, F. J. J. de Kanter, C. V. Stevens, M. Swart, F. M. Bickelhaupt, M. B. Groen and R. V. A. Orru, J. Org. Chem., 2005, 70, 3542.

65 L. A. Allinger, X. Zhou and J. Bergsma, J. Mol. Struct. (THEOCHEM), 1994, 312, 69.

66 L. S. Erre, G. Micera, E. Garriba and A. C. Bényei, New J. Chem., 2000, 24, 725.

67 (a) J. G. Brennan, R. A. Andersen and J. L. Robbins, J. Am. Chem Soc., 1986, 108, 335; (b) J. Parry, E. Carmona, S. Coles and M. Hursthouse, J. Am. Chem. Soc., 1995, 117, 2649.

68 T. Mehdoui, J.-C. Berthet, P. Thuéry and M. Ephritikhine, Dalton Trans., 2005, 1263

69 B. E. Bursten and R. J. Strittmatter, J. Am. Chem. Soc., 1987, 109, 6606.

70 R. G. Pearson, Proc. Natl. Acad. Sci. U. S. A., 1986, 83, 8440.

71 (a) L. Maron and O. Eisenstein, New J. Chem., 2001, 25, 255; (b) O. Eisenstein and L. Maron, J. Organomet. Chem., 2002, 647, 190. 


\title{
DFT modeling of the relative affinity of nitrogen ligands for trivalent $f$ elements: an energetic point of view
}

\author{
Laurence Petit, Claude Daul, Carlo Adamo and Pascale Maldivi
}

\section{SUPPLEMENTARY INFORMATION}

Supplementary information 1. Detailed results for $\left[\mathrm{La}(\mathrm{MeBTP})_{3}\right]^{3+}$ in a vacuum and in pyridine solvent (COSMO). Experimental values ${ }^{23}$ are mentioned in parentheses.

\begin{tabular}{|c|c|c|}
\hline & {$\left[\mathrm{La}(\mathrm{MeBTP})_{3}\right]^{3+}$, vacuum } & {$\left[\mathrm{La}(\mathrm{MeBTP})_{3}\right]^{3+}$, pyridine Cosmo } \\
\hline \multicolumn{3}{|c|}{ Optimized geometries } \\
\hline $\mathrm{d}\left(\mathrm{M}-\mathrm{N}_{\mathrm{c}}\right), \AA$ & $2.68(2.67)$ & $2.68(2.67)$ \\
\hline $\mathrm{d}\left(\mathrm{M}-\mathrm{N}_{\mathrm{l}}\right), \AA$ & $2.66(2.63)$ & $2.66(2.63)$ \\
\hline \multicolumn{3}{|c|}{ Mulliken charges } \\
\hline $\mathrm{q}(\mathrm{M}),\left|\mathrm{e}^{-}\right|$ & 2.00 & 1.98 \\
\hline $\mathrm{q}(\mathrm{MeBTP}),\left|\mathrm{e}^{-}\right|$ & 0.33 & 0.34 \\
\hline \multicolumn{3}{|c|}{ Energetic analysis } \\
\hline$\Delta$ Epauli, $_{\mathrm{eV}}$ & 8.74 & 8.90 \\
\hline$\Delta$ Eelec, $\mathrm{eV}$ & -17.84 & -19.70 \\
\hline$\Delta$ Esteric, $_{2} \mathrm{eV}$ & -9.11 & -10.79 \\
\hline$\Delta \mathrm{E}_{\text {orb }}, \mathrm{eV}$ & -20.54 & -18.98 \\
\hline$\Delta \mathrm{E}_{\text {solv }}(\mathrm{el})^{*}, \mathrm{eV}$ & - & 16.76 \\
\hline$\Delta \mathrm{E}_{\text {solv }}(\mathrm{cd})^{*}, \mathrm{eV}$ & - & 0.18 \\
\hline$\Delta \mathrm{E}_{\text {tot }}, \mathrm{eV}$ & -29.64 & -12.84 \\
\hline \multicolumn{3}{|l|}{ Orbital analysis } \\
\hline & No backdonation & No backdonation \\
\hline & $\begin{array}{c}\text { Donation } \\
0.18\left|\mathrm{e}^{-}\right| \text {on } \mathrm{d}(\mathrm{La}) \text { orbitals }\end{array}$ & $\begin{array}{c}\text { Donation } \\
0.18|\mathrm{e}-| \text { on } \mathrm{d}(\mathrm{La}) \text { orbitals }\end{array}$ \\
\hline
\end{tabular}

\footnotetext{
${ }^{*} \mathrm{el}$ : electrostatic term in the solvation energy - cd : cavitation and dispersion terms in the solvation energy
} 
Supplementary information 2. Energetic decomposition of the different contributions involved in the complexation process of $\mathrm{M}^{3+}$ by 3 ligands. Details relative to cerium complexes in the optimized geometry of uranium systems and of uranium complexes in the optimized geometry of cerium systems is also given. For comparison, the evolution of back-bonding effects is shown.

\begin{tabular}{|c|c|c|c|c|}
\hline & $\mathrm{M}=\mathrm{Ce}$ & $\mathrm{M}=\mathrm{U}$ & $\begin{array}{l}\mathrm{M}=\mathrm{Ce} \text { in } \mathrm{U} \\
\text { geometry }\end{array}$ & $\begin{array}{l}\mathrm{M}=\mathrm{U} \text { in } \mathrm{Ce} \\
\text { geometry }\end{array}$ \\
\hline \multicolumn{5}{|l|}{$\left[M(\text { Terpy })_{3}{ }^{\beta+}\right.$} \\
\hline$\Delta$ EPauli, $\mathrm{eV}$ & 48.61 & 63.46 & 57.21 & 53.63 \\
\hline$\Delta$ Eelec, $_{\text {eV }}$ & -20.37 & -23.76 & -23.48 & -20.36 \\
\hline$\Delta$ Esteric, $\mathrm{eV}$ & 28.24 & 39.70 & 33.72 & 33.27 \\
\hline$\Delta \mathrm{E}_{\text {orb }}, \mathrm{eV}$ & -57.56 & -70.31 & -63.33 & -63.22 \\
\hline$\Delta \mathrm{E}_{\text {bonding, }} \mathrm{eV}$ & -29.32 & -30.62 & -29.60 & -29.94 \\
\hline Back-bonding, $\left|\mathrm{e}^{-}\right|$ & 0.08 & 0.48 & 0.16 & 0.30 \\
\hline \multicolumn{5}{|l|}{$\left[M(M e B T P)_{3}{ }^{\beta+}\right.$} \\
\hline$\Delta$ Epauli, $_{\text {eV }}$ & 52.24 & 68.79 & 61.79 & 57.84 \\
\hline$\Delta$ Eelec, $\mathrm{eV}$ & -21.64 & -25.50 & -25.03 & -21.77 \\
\hline$\Delta \mathrm{E}_{\text {steric }}, \mathrm{eV}$ & 30.60 & 43.29 & 36.76 & 36.08 \\
\hline$\Delta \mathrm{E}_{\text {orb }}, \mathrm{eV}$ & -61.52 & -75.23 & -67.45 & -67.88 \\
\hline$\Delta$ Ebonding, $_{\text {, }} \mathrm{eV}$ & -30.91 & -31.94 & -30.69 & -31.80 \\
\hline Back-bonding, $\left|\mathrm{e}^{-}\right|$ & 0.16 & 0.59 & 0.25 & 0.47 \\
\hline \multicolumn{5}{|l|}{$\left[M(H B T P)_{3}\right]^{3+}$} \\
\hline$\Delta$ Epauli, $_{\text {eV }}$ & 51.35 & 67.30 & & \\
\hline$\Delta$ Eelec, $_{\text {eV }}$ & -21.29 & -24.95 & & \\
\hline$\Delta E_{\text {steric }}, \mathrm{eV}$ & 30.06 & 42.35 & & \\
\hline$\Delta \mathrm{E}_{\text {orb }}, \mathrm{eV}$ & -58.86 & -72.27 & & \\
\hline$\Delta \mathrm{E}_{\text {bonding, }} \mathrm{eV}$ & -28.79 & -29.92 & & \\
\hline
\end{tabular}


Supplementary information 3. Percentage contributions of the electrostatic and orbital terms to the metal-ligand bond.

\begin{tabular}{lcccccc}
\hline & {$\left[\mathrm{Ce}(\text { terpy })_{3}\right]^{3+}$} & {$\left[\mathrm{U}(\text { terpy })_{3}\right]^{3+}$} & {$\left[\mathrm{Ce}(\mathrm{MeBTP})_{3}\right]^{3+}$} & {$\left[\mathrm{U}(\mathrm{MeBTP})_{3}\right]^{3+}$} & {$\left[\mathrm{Ce}(\mathrm{HBTP})_{3}\right]^{3+}$} & {$\left[\mathrm{U}(\mathrm{HBTP})_{3}\right]^{3+}$} \\
\hline \%elec & 26.1 & 25.3 & 26.0 & 25.3 & 26.6 & 25.7 \\
\hline \%orb & 73.9 & 74.7 & 74.0 & 74.7 & 73.4 & 74.3 \\
\hline
\end{tabular}

